\title{
Specific mechanical properties of superplastically formed components and resulting applications for vehicles
}

\author{
Kyrylo Vorobyov ${ }^{1, a}$, Valentyn Danchenko ${ }^{2, b}, E^{2}$ mar Beeh ${ }^{1, c}$ and Gundolf \\ $\mathrm{Kopp}^{1, \mathrm{~d}}$ \\ ${ }^{1}$ Institute of Vehicle Concepts, German Aerospace Center, Pfaffenwaldring 38-40, 70569 Stuttgart, \\ Germany \\ ${ }^{2}$ Metal Forming Department, National Metallurgical Academy of Ukraine, 4 Gagarin ave., 49600 \\ Dnipropetrovsk, Ukraine \\ aKyrylo.Vorobyov@dlr.de, ${ }^{\text {b }}$ plastform@mail.ru, ${ }^{\mathrm{c}}$ Elmar.Beeh@dlr.de, ${ }^{\mathrm{d}}$ Gundolf.Kopp@dlr.de
}

Keywords: Severe plastic deformation.

Abstract. The technical requirements to produce parts as light as possible with more complex geometries are ever increasing in recent years in automotive industries, rail vehicle and aerospace. Manufacturing technologies such as super-plastic metal forming, which had been considered as a niche technology earlier, is now gaining greater technical relevance for industrial size production. The parts that have been generated through super-plastic forming in innovative vehicle for example Mercedes SLS AMG reflect the industrial activity in this area. Manufacturability of thin-walled structures enables lightweight design. Also the tool and manufacturing costs are lower in comparison. However, the main challenge could be found in maintaining exact process parameters. There is a large research potential in super-plastic forming; from the determination of optimal material data through process simulation to manufacturing of real parts and their characterization. In the framework of the project international Bureau of the Federal Ministry of Education and Research UKR005/08 "Manufacture of parts with special properties" a preliminary research work has been carried out.

The scientific challenge lies in the characterisation of forming properties of light metal alloys in super-plastic forming. In this preliminary research, the "full factorial experiment" methodology has been applied, regression equations have been developed and a mathematical model derived. This shows interrelationship between mechanical properties of the material and the variable process parameters, leading to material characterization. Hence advantages of cost and time have been achieved; the important parameters for the design of parts through super-plastic forming are determined. The analytical results are then verified with finite element method - simulations and through experiments with general parts.

The basic structure of a typical car's chassis consists of more than 200 individual parts. This large number of components results mainly from the limited deformation capacity of sheet metal, thus requiring the complex structure of the chassis to be subdivided into a large number of components. There is a motivation at present to develop a vehicle structure such that the chassis consists of only a small number of components of complex shape. The low investment costs required for the tools used in this process allow a decentralised, market-oriented and flexible manufacturing process for the whole chassis. Thus innovations can reach the market faster.

The research challenge is to make construction methods used up until now for small series manufacturing (such as monocoque and mixed production) applicable to medium and later largescale usage [1].

This approach to vehicle construction was further pursued by the German Aerospace Center at its Institute of Vehicle Concepts (DLR-FK) for the manufacture of components with complex geometries in rail vehicle construction, applying it to the specialised requirements of that sector. The structure of access connections between rail wagons and of drivers' cabs in high-speed trains 
both represent potential areas of application to help fulfil the demanding technical and aerodynamic requirements in this area [2].

The approach followed is distinct from current constructions and vehicle production methods. The flexibility of the process will allow different materials can be introduced in the future, thus permitting elements to be replaced according to the availability of a particular material. Its capacity to implement new constructions quickly may also play a major role in future mobility scenarios.

Super plastic forming is a type of pressure form process by which metallic sheet materials are formed using high pressures and temperatures, the latter being generally above recrystallisation temperature $(\mathrm{T}>0.5 \mathrm{Tmelt})$.

Preconditions for the use of super-plastic forming include [3]:

- Fine, equiaxial grains with a size $\leq 10 \mu \mathrm{m}$

- A highly stable structure and resistance to pore formation

- Precise control of temperature and forming speed during the process.

A particular challenge for the creation of innovative lightweight structures using super-plastic forming is the adjustment of the process to deal with different aluminium and magnesium alloys. The most accurate possible characterisation of materials will be required to achieve reliable component design.

For development and verification of the methodology for calculating manufacturing parameters, two aluminium alloys (AA5754 and AA5083-SPF) and one magnesium alloy, AZ31, were selected. The aluminium alloy AA5083-SPF was developed especially for the process and taken as the reference alloy.

The main factors influencing the plastic behaviour of the metallic materials at high temperatures include the chemical make-up of the alloy, the temperature and the extent and speed of deformation. Mechanical properties were obtained using tensile testing following DIN EN 10002. The "full factorial experiment" methodology was used in trials [4-6]. The analytic regression equations were built up with the help of this methodology. In this way, tests in which not all processes affecting in the material are known can be used to build up and analyse mathematical models. The mathematical models represent the dependencies between the mechanical properties of a material and the process parameters, leading up to a characterisation of the material (including, e.g., its max. deformation or strength properties).

A "full factorial experiment plan" was drawn up to represent the mathematical models (Table 1).

Table 1: "Full factorial experiment plan"

\begin{tabular}{|l|l|l|l|l|l|l|l|}
\hline № & $\mathrm{X}_{0}$ & $\mathrm{X}_{1}$ & $\mathrm{X}_{2}$ & $\mathrm{X}_{1} \mathrm{X}_{2}$ & $\mathrm{Y}_{1}$ & $\mathrm{Y}_{2}$ & $\mathrm{Y}_{3}$ \\
\hline \multicolumn{7}{|c|}{ AA 5754 } \\
\hline 1 & +1 & +1 & +1 & +1 & 116.6 & 136.2 & 70.1 \\
\hline 2 & +1 & -1 & +1 & -1 & 249.0 & 288.3 & 8.5 \\
\hline 3 & +1 & +1 & -1 & -1 & 118.4 & 129.8 & 76.0 \\
\hline 4 & +1 & -1 & -1 & +1 & 248.3 & 285.8 & 14.5 \\
\hline \multicolumn{7}{|c|}{ AA 5083 } \\
\hline 1 & +1 & +1 & +1 & +1 & 114.4 & 132.2 & 98.4 \\
\hline 2 & +1 & -1 & +1 & -1 & 145.0 & 274.0 & 32.0 \\
\hline 3 & +1 & +1 & -1 & -1 & 96.5 & 97.7 & 114.4 \\
\hline 4 & +1 & -1 & -1 & +1 & 138.4 & 285.8 & 63.3 \\
\hline \multicolumn{7}{|c|}{ AZ 31 } \\
\hline 1 & +1 & +1 & +1 & +1 & 64.4 & 77.3 & 78 \\
\hline 2 & +1 & -1 & +1 & -1 & 138.2 & 255.2 & 36 \\
\hline 3 & +1 & +1 & -1 & -1 & 55.5 & 62.1 & 96.6 \\
\hline 4 & +1 & -1 & -1 & +1 & 124.8 & 240.8 & 59.42 \\
\hline
\end{tabular}

$Y_{1}$ - yield stress

$Y_{2}$ - tensile strength

$Y_{3}$ - strain 
With the help of this plan, mathematical regressions can be built up according to the following principle (1):

$$
\mathrm{Y}=\mathrm{b}_{0}+\mathrm{b}_{1} \mathrm{X}_{1}+\mathrm{b}_{2} \mathrm{X}_{2}+\mathrm{b}_{1,2} \mathrm{X}_{1} \mathrm{X}_{2} \text {, where }
$$

$\mathrm{Y}$ is a function of yield point, tensile strength, and stretching. The flow behaviour of the selected alloys grows almost linearly with increase in temperature and decrease in strain rate; for this reason, only the coefficients $b_{0}, b_{1}, b_{2}, b_{1,2}$ need to be determined. Factors $X_{1}$ and $X_{2}$ represent the temperatures in the range from $20{ }^{\circ} \mathrm{C}-250{ }^{\circ} \mathrm{C}$ and for strain rates in the range $10^{-2}-10^{-4} \mathrm{~s}^{-1}$. On this basis, the following regression equations were obtained for the alloys used:

\section{1). Aluminium alloy AA 5754}

$\mathrm{Y} 1=183.065-65.58 \mathrm{X}_{1}-0.265 \mathrm{X}_{2}-0.615 \mathrm{X}_{1} \mathrm{X}_{2}$;

$\mathrm{Y} 2=210.04-77.02 \mathrm{X}_{1}-2.226 \mathrm{X}_{2}+0.96 \mathrm{X}_{1} \mathrm{X}_{2}$

$\mathrm{Y} 3=42.28+30.78 \mathrm{X}_{1}-2.988 \mathrm{X}_{2}-0.018 \mathrm{X}_{1} \mathrm{X}_{2}$;
2). Aluminium alloy AA 5083

$$
\begin{aligned}
& \mathrm{Y} 1=123.58-18.13 \mathrm{X}_{1}+6.11 \mathrm{X}_{2}+2.83 \mathrm{X}_{1} \mathrm{X}_{2} ; \\
& \mathrm{Y} 2=197.425-82.475 \mathrm{X}_{1}+5.675 \mathrm{X}_{2}+11.58 \mathrm{X}_{1} \mathrm{X}_{2} ; \\
& \mathrm{Y} 3=77.03+29.38 \mathrm{X}_{1}-11.83 \mathrm{X}_{2}+3.83 \mathrm{X}_{1} \mathrm{X}_{2} ;
\end{aligned}
$$

\section{3). Magnesium alloy AZ31}

$\mathrm{Y} 1=95.725-35.775 \mathrm{X}_{1}+5.575 \mathrm{X}_{2}-1.125 \mathrm{X}_{1} \mathrm{X}_{2}$

$\mathrm{Y} 2=158,85-59,15 \mathrm{X}_{1}+7,4 \mathrm{X}_{2}-0,2 \mathrm{X}_{1} \mathrm{X}_{2}$;

$\mathrm{Y} 3=67.505+19.795 \mathrm{X}_{1}-10.505 \mathrm{X}_{2}+1.205 \mathrm{X}_{1} \mathrm{X}_{2}$;

It is clear from the regressions and coefficients described above for the mathematical model that with Al Alloy AA5754 the strain rate has less influence on mechanical properties than the temperature of deformation. This allows variations to be made to the strain rate used in the process (i.e. allows it to be increased) without adversely affecting mechanical properties. In contrast to this, the mechanical properties of Aluminium alloy AA5083-SPF and AZ31 display a strong dependency on the strain rate. Where the strain rate is increased by a factor of 10 , then the maximum possible stretching is reduced by a factor of 1.3. For this reason, the strain rate will need in the case of these alloys to be more closely observed when drawing up the process parameters.

The mathematical regressions allow conclusions to be made on the mechanical properties of the selected alloys on the basis of dependencies in the process parameters (involving temperature and strain rate). Thus, for example, the consequences of changes in temperature on the plastic behaviour of the selected alloys can be calculated (Fig. 1).

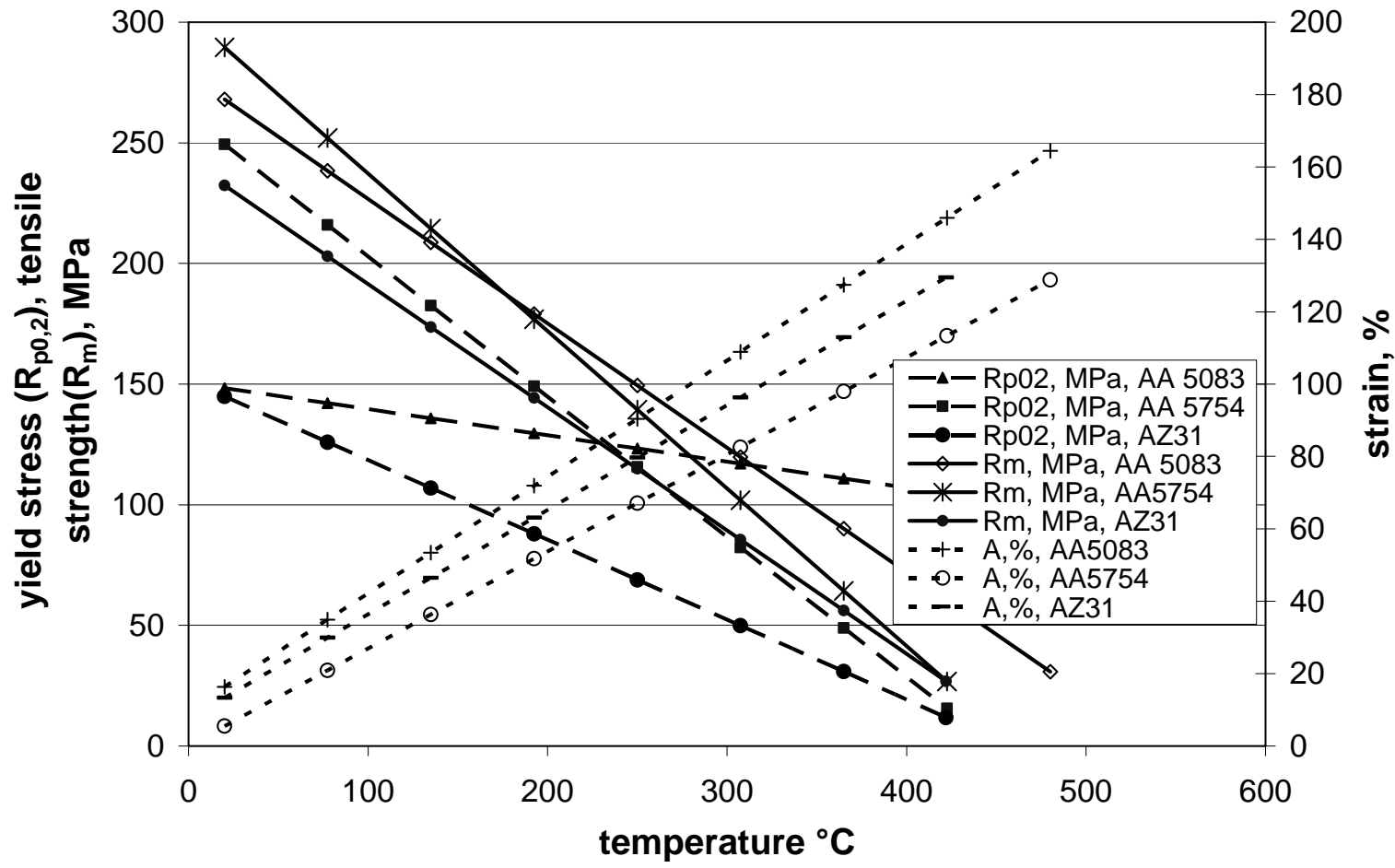

Fig.1: Mechanical properties calculated for the tested materials in relation to temperature 
For checking the results of the analytical calculations and optimisation of the process parameters, a test range suitable for high-temperature testing was constructed; this range allowed the production of complex sample pieces (Fig.2).

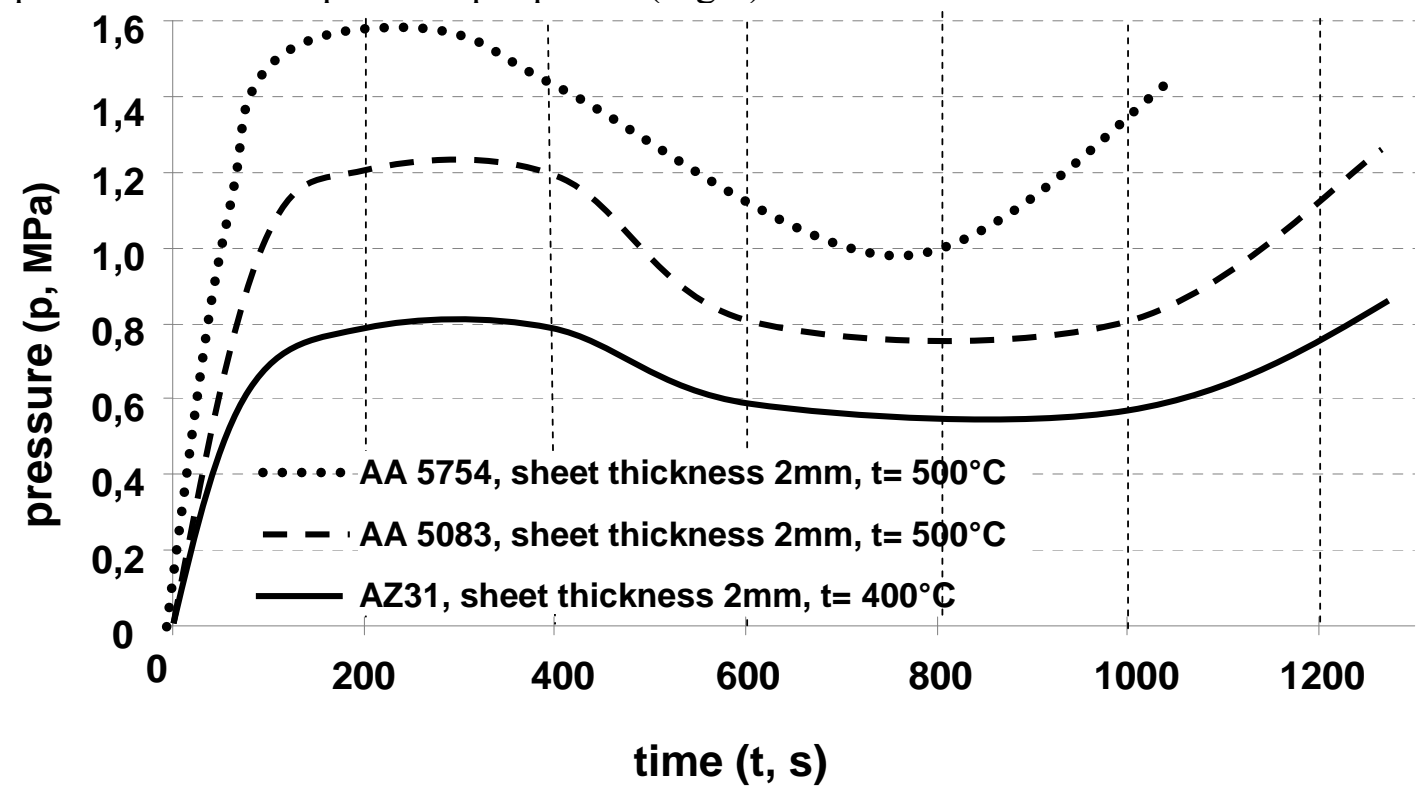

Fig.2: The pressure-time curve for deformation of cylindrical sample pieces made out of the test materials.

With the help of the methodology, alloys can be characterised quickly and reliably and their deformation parameters can be thus identified. As Fig. 2 shows, sample pieces made of Al alloy AA5754 could be formed in the test range more quickly (by a factor of 1.2).

For the tests, a measuring grid (grid size $\varnothing=1 \mathrm{~mm}$ ) was set out on the sheet and analysed after the test. The sample pieces created in the test exhibit the max. possible distortions previously obtained by analysis (Fig.1). Fig.3 shows a sample piece of the Mb alloy AZ31 with a max. distortion of $180 \%$ and a snippet from the FEM simulation model.

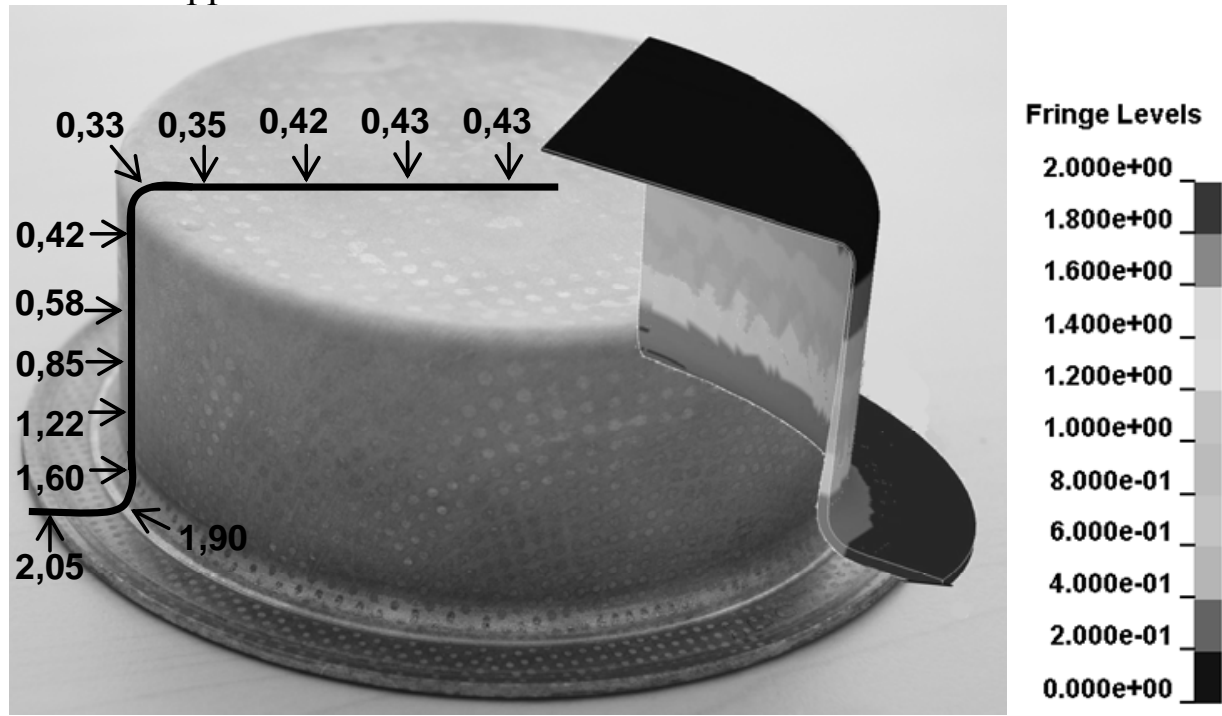

Fig.3: Comparison between experimental and FEM simulation (cylindrical sample pieces, Mg alloy AZ31)

The sample pieces produced in the test range correspond well with the results of the analytical calculation and the FEM simulation.

In addition to these process parameters, knowledge of material properties after super-plastic forming will also be an important consideration. The material properties of the formed components may be different from those of the unformed sheets and will depend additionally on the deformation 
parameters. The influence of the deformation parameters on material properties is clear when deforming the $\mathrm{Mg}$ sheets (AZ31). Material properties after deformation were obtained in tensile testing. Before tensile testing, the test pieces are warmed to a testing temperature of $250{ }^{\circ} \mathrm{C}$. The strain rates were $10^{-2} \mathrm{~s}^{-1}$ and $10^{-4} \mathrm{~s}^{-1}$. During testing, the test pieces were pre-stretched at a constant temperature by $50 \%$ in relation to their initial state. To obtain the material properties after deformation using both strain rates of the pre-drawn plates, flat tensile test pieces were cut out following DIN EN 10 002-1 using the water jet cutting device. The tensile tests on outcut samples were executed at room temperature using the tensile testing device ZWICK 250 at DLR-FK. The results obtained are displayed on Fig.4.

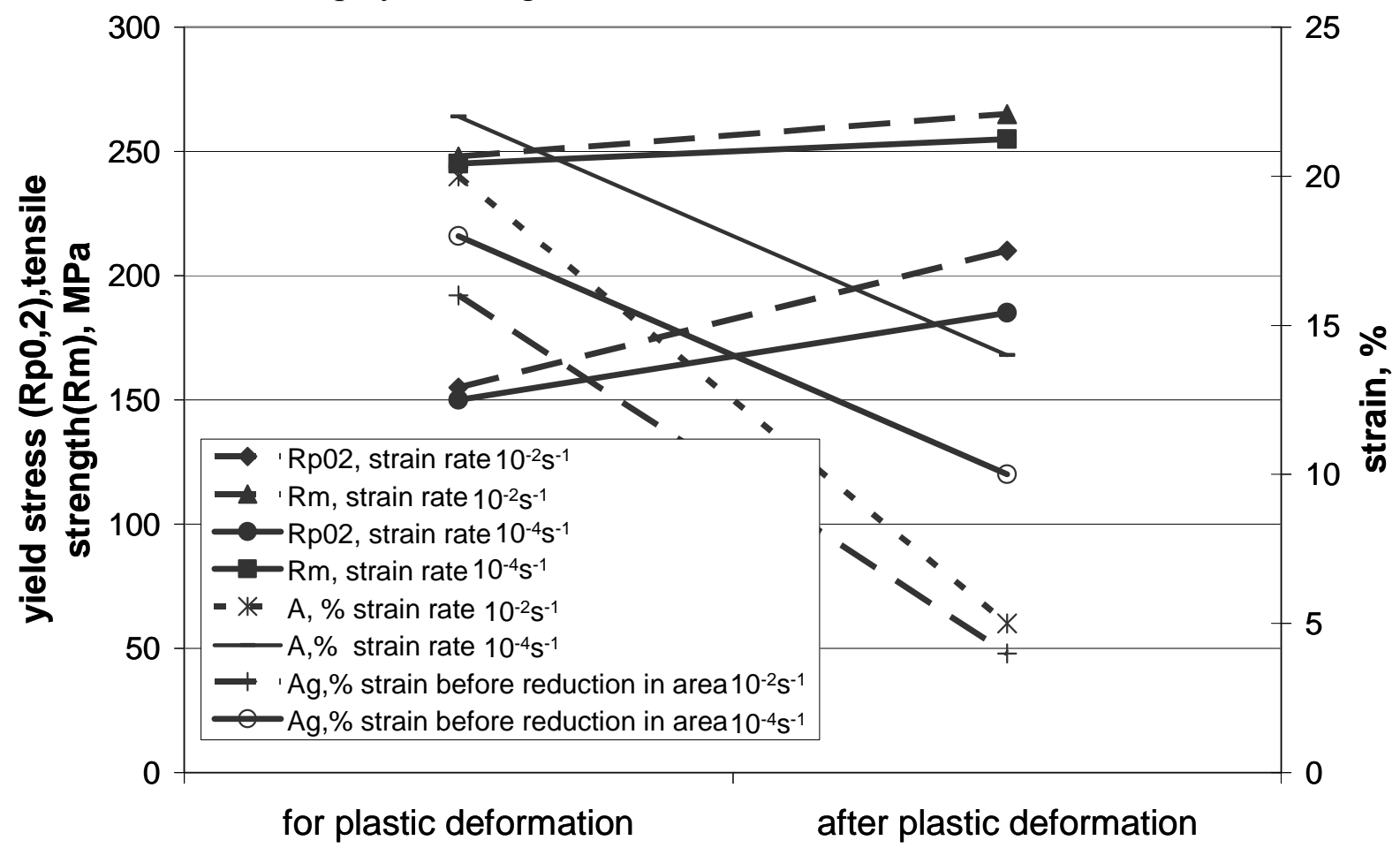

Fig.4: Dependency of yield and tensile strength and stretching on the strain speed $(\mathrm{Mg}$ alloy AZ31)

A clear tendency can be seen from the yield and tensile strength of samples. It is clear that pieces deformed at the higher speed of $10^{-2} \mathrm{~s}^{-1}$ have considerably higher yield and tensile strength values than the initial material and than the pieces deformed at the lower rate of $10^{-4} \mathrm{~s}^{-1}$. Accounting for the higher yield strength, however, is the fact that sheets were not fully softened during recrystallisation processes when stretched at $225-250{ }^{\circ} \mathrm{C}$, and thus a degree of work hardening remained in the material after the forming process. The reason for the strength of the magnesium samples is also explained by its hexagonal mesh structure which - in contrast to the good deformation properties of the face-centred cubic structure of the aluminium - accounts for its limited deformation capacity at room temperature. Up to a temperature of $225^{\circ} \mathrm{C}$, a sliding occurred mainly along the base plane in the direction of the most tightly packed rows of atoms. A further additional deformation mechanism at room temperature is twinning. Only at temperatures of more than $225^{\circ} \mathrm{C}$ do additional sliding levels become active, thus allowing improved deformability. This effect is due to increased mobility of the atoms in the matrix. Thus the metal has a very high level of deformability at temperatures above $225^{\circ} \mathrm{C}$. Sliding is also possible via shifts occurring at prismatic levels. At a temperature of about $250{ }^{\circ} \mathrm{C}$ and using low stretching speeds, it is suspected that an alternative, pyramidal and prismatic sliding has occurred in the magnesium crystal. This is evidenced in the result by the fact that the remaining work hardening is substantially higher in sheets formed at high speed than in super-plastic formed sheets [7].

On analysing stretch at break it is also clear that test pieces drawn at the higher speed show an additional stretch at break of about 5\% after the deformation. The reduction in the stretch at break 
can be explained by the flow behaviour of the material. Even once additional flow planes become active in the selected alloys, a maximum stretching of up to $60 \%$ was achieved in the hot tensile test at a temperature of $250{ }^{\circ} \mathrm{C}$. Necking areas appeared on drawing strips by $50 \%$, leading to varying sheet thicknesses in the samples.

With the low strain rate (within the super-plastic domain), the samples achieve a substantially higher level of stretching of up to $135 \%$. The material flow was much more regular in the mechanisms described above. When analysing the stretching behaviour of the super-plastically formed sheets, it can be seen that the material exhibits a sufficient stretch at break after superplastic forming. Material properties needed for later operations involving conventional processes carried out on components remain unaffected.

\section{Summary and Outlook}

In this paper, the deformation properties of lightweight metal alloys (AA5083-SPF, AA5754 and AZ31) using super-plastic sheet forming were presented. Regression equations were shown and mathematical comparison models were derived, representing the dependencies between mechanical properties of the material and variable process parameters. Time and cost advantages can be achieved by using the result of these experiences and improvements in processes in series production. The most important parameters for the development of super-plastic formed components were identified and made available.

\section{Bibliography}

[1] H. Friedrich, P. Steinle, G. Kopp, R. Schöll: Next decades' challenges for terrestrial vehicles' materials and manufacturing to reduce CO2 emissions. In: Journal of Materials Science Forum . Thermec 2009 International Conference on Processing \& Manufacturing of Advanced Materials, 25.-29.08.2009, Berlin.

[2] J. Nickel, J. Koenig: Innovative lightweight construction concept for the railcar body of the Next Generation Train (NGT) and possibilities for lightweight Rating (German), 11. Internationale Schienenfahrzeugtagung, Dresden, 23. - 25.02.2011

[3] H. Friedrich: Development of superplastic aluminum forming in the aerospace (German), Werkstatt und Betrieb, 1990, 123, pp. 945-948.

[4] F. Novik, J. Arsov: Process optimization technology of metals planning methods of the experiment (Russian), Mashinostroenie, Moscow, 1980.

[5] O. Kuzmina,V. Grynkevych: Investigation of the influence parameters of hot deformation on uneven structure of the billets by means of numerical simulation (Russian), In: Sistemni tehnologii. 2005. T.8. pp. 484.

[6] V. Danchenko, A. Milenin, V. Kuzmenko, V. Grynkevych: Computer simulation of metal forming (Russian), In: Systemni tehnologii, 2005. pp. 448.

[7] Novikov I. I., Portnoj V. K.: super plasticity of the alloys. VEB, Leipzig 1985. 